\title{
A Study of the Clinico-Bacteriological Profile of Infants Aged 29-59 Days Suffering from Very Severe Disease According to WHO IMCI Guideline
}

\author{
Rokshana $A^{a}$, Enshad EU ${ }^{b}$, Muhammad Jabed $A C^{b}$, Pronab $K^{b}$, \\ ${ }^{a}$ Chattagram International Medical College Hospital, Chittagong, Bangladesh \\ ${ }^{\mathrm{b}} \mathrm{Chittagong}$ Medical College Hospital, Chittagong, Bangladesh
}

ABSTRACT

INTRODUCTION: According to the IMCI guidelines young infants below 2 months are considered a special group because these infants have special characteristics, that they can become sick and die very quickly from serious bacterial infections. This descriptive cross-sectional study was carried out to assess clinical characteristics of very severe disease according to WHO IMCI guideline among young infants of 29-59 days age and to determine whether clinically severe infections are associated with culture-positive bacteremia as well as to find out common etiological factors including organisms involved. The rationale behind conducting such research was that, although young infants of 29-59 days were equally vulnerable to severe infections as are the neonates; similar research addressing the condition in the young infants of the mentioned age is generally lacking. METHODS AND MATERIALS: This was a descriptive cross-sectional study conducted in the Department of Pediatrics, Chittagong Medical College Hospital, from March 2016 to September 2016. Young infants aged between 29-59 days presenting with signs of very severe disease were enrolled. Exclusion criteria were young infants with a congenital anomaly and very sick infants. RESULTS: In this study, it was observed that the majority (43.8\%) of patients belonged to age 31-40 days and the mean age was $42.2 \pm 7.4$ days, ranged from 30 to 57 days. Regarding the sign of severe infection, the majority (97.7\%) of patients had a fever, followed by $81.6 \%$ fast breathing, $65.5 \%$ history of unable to feed, $29.9 \%$ convulsion, $27.6 \%$ movement when stimulated, $18.4 \%$ grunting, and $2.3 \%$ had low body temperature. Eleven patients were found in blood culture positive. Klebsiella spp. was the most prevalent pathogens, comprising 6(54.5\%) of the isolates, followed by coliform 2(18.2\%), staphylococcus aureus 2(18.2\%), and coagulase -ve staphylococcus was 1

(9.1\%). CONCLUSION: Fever, fast breathing, and unable to feed were more common signs of very severe disease in the patients and positive blood culture was found in $12.6 \%$ of the cases. Klebsiella was found to be the commonest pathogen.

KEYWORDS: antimicrobial susceptibility, mortality, young infant sepsis.

\section{INTRODUCTION}

Neonatal period is defined by the age of infants at 0 days to 28 days. It is the time when the infants are particularly vulnerable to serious infections. ${ }^{1,2,10}$ First week of life has the highest vulnerability to acquire serious infections

\section{Corresponding Author:}

Asst. Prof. Dr. Rokshana Ahmed Equity Fortuna 100, Flat \# B4, Panchlaish, Chittagong, Bangladesh. Chattagram International Medical College Hospital 206/1, Haji Chandmeah road, Shamser para, Darul Marif, Chandgaon, Chittagong, Bangladesh.

Tel No : +8801946999553

E-mail : drrokshanaahmed@gmail.com which are called "early-onset neonatal sepsis", with very high mortality. ${ }^{7,14}$ As for the neonates, the infants at the second month are also at a higher risk of mortality from infections than at later ages. ${ }^{2,20}$ It has been suggested that immunologically naive neonates and young infants are particularly susceptible to bacterial infections because the immune system requires the first two to three months of infantile life to steadily mature up. ${ }^{9}, 11,12,20$ The Integrated Management of Childhood Illness (IMCI), formulated by WHO since 1992 has divided the under 5 children into two separate groups for the management of childhood illnesses, that is IMJM Volume 20 No.1, Jan 2021 
children aged 2 months up to 5 years and that of young infants below 2 months of age. ${ }^{18}$ According to this guideline, this stratification is because of the very idea that the young infants below 2 months have the same special characteristics, that they can become sick and die very quickly from serious bacterial infections. ${ }^{19}$ It is necessary to develop research priorities to understand the critical aspects of the clinico-bacteriological presentations of "very severe disease" in this age group, for the prevention of similar infections in the future.

Neonates are vulnerable to serious infections as are infants of 29-59 days of age. Considering the fact, an ample amount of research has been done on neonatal infections both in the developed as well as in the developing countries. But little or no such research has been found on serious infections in infants of 29-59 days of age. Furthermore, such studies on "very severe disease" according to IMCI guidelines in infants of 2959 days are ever more deficient in Bangladesh. This study was conducted to understand the clinicobacteriological profile of "very severe disease" according to IMCI guidelines in the vulnerable age group of 29-59 days, in Bangladeshi patients.

\section{METHODS AND MATERIALS}

This was a descriptive cross-sectional study conducted in the Department of Pediatrics, Chittagong Medical College Hospital (CMCH), from March 2016 to September 2016. Informed written consent was obtained from a parent or legal guardian of each patient who enrolled in the study. Young infants aged between 29-59 days presenting with signs of very severe disease defined as having either "convulsion, not feeding well/ unable to feed, grunting, fast breathing, fever $>99.5^{\circ} \mathrm{F}$ $\left(37.22^{\circ} \mathrm{C}\right)$ or feels hot, low body temperature $<95^{\circ} \mathrm{F}$ $\left(35^{\circ} \mathrm{C}\right)$ or feels cold, movement when stimulated or no movement at all" were enrolled consecutively as the study population. Exclusion criteria were young infants with a congenital anomaly and very sick infants. According to the present inclusion and exclusion criteria, this study included 87 infants. History and clinical examination findings were noted in a case record form. Blood was collected with all aseptic precautions for doing blood culture. Blood culture was done in chocolate, blood, and McConkey agar media by lysis direct plating method under strict quality control. The IMJM Volume 20 No.1, Jan 2021 results of blood culture were included in the appropriate sections of the case record form.

\section{DATA ANALYSIS}

Statistical analyses were carried out by using the Statistical Package for Social Sciences version 20.0 for Windows (SPSS Inc., Chicago, Illinois, USA). The mean values were calculated for continuous variables. The quantitative observations were indicated by frequencies and percentages. Chi-Square test with Yates correction was used to analyze the categorical variables, shown with cross-tabulation. Student t-test was used for continuous variables. A p-value of $<0.05$ was considered statistically significant.

\section{ETHICAL IMPLICATIONS}

Informed written consent was obtained from each parent before enrolment into the study. Ethical clearance for the study was taken from the Ethical Committee of Chittagong Medical College.

\section{RESULTS}

\section{Distribution of the study population by demographic variables}

It was observed that the majority $(43.8 \%)$ of patients belonged to age 31-40 days. The mean age of the study population was found to be $42.2 \pm 7.4$ days with a range from 30 to 57 days. $55.2 \%$ of patients were male and 39 $(44.8 \%)$ were female. $79.3 \%$ of the mothers were housewives and $18(20.7 \%)$ were service holders. 82.8\% of the patients were rural and $15(17.2 \%)$ were from the urban area. The majority $(80.5 \%)$ of the patients were delivered at home and $17(19.5 \%)$ had had institutional delivery. $96 \%$ of the study population received appropriate umbilical care.

\section{Signs of very severe disease according to $\mathrm{IMCl}$ guideline in the study population}

The majority $(97.7 \%)$ of the patients had a fever, 71 (81.6\%) had fast breathing, $57(65.5 \%)$ had unable to feed, $26(29.9 \%)$ had a convulsion, $24(27.6 \%)$ had 
movement when stimulated, 16 (18.4\%) had grunting and $2(2.3 \%)$ had low body temperature. majority $(97.7 \%)$ patients had a fever, $71(81.6 \%)$ had fast breathing, 57 (65.5\%) had unable to feed, 26 (29.9\%) had a convulsion, $24(27.6 \%)$ had movement when stimulated, $16(18.4 \%)$ had grunting and $2(2.3 \%)$ had low body temperature (Please refer Table I).

Table I : Signs of austere disease in the study population $(\mathrm{n}=87)$

\begin{tabular}{lcc}
\hline $\begin{array}{l}\text { Sign of Severe } \\
\text { Infection }\end{array}$ & $\begin{array}{l}\text { Number } \\
\text { of } \\
\text { patients }\end{array}$ & Percentage \\
\hline Fever & 85 & 97.7 \\
Fast breathing & 71 & 81.6 \\
Unable to feed & 57 & 65.5 \\
Convulsion & 26 & 29.9 \\
$\begin{array}{l}\text { Movement when } \\
\text { stimulated }\end{array}$ & 24 & 27.6 \\
Grunting & 16 & 18.4 \\
Low body & 2 & 2.3 \\
temperature & & \\
\hline
\end{tabular}

\section{Distribution of the study patients by blood culture}

$11(12.6 \%)$ patients had positive blood culture and 76 $(87.4 \%)$ were negative for blood culture (Please refer Table II).

Table II: Distribution of the study patients by blood culture $(\mathrm{n}=87)$

\begin{tabular}{lcc}
\hline $\begin{array}{l}\text { Blood } \\
\text { culture }\end{array}$ & $\begin{array}{c}\text { Number } \\
\text { of } \\
\text { patients }\end{array}$ & Percentage \\
\hline Positive & 11 & 12.6 \\
Negative & 76 & 87.4 \\
\hline
\end{tabular}

\section{Organisms found in culture-positive cases}

Eleven patients were found in blood culture positive. Among them 6 (54.5\%) were Klebsiella spp., 2 (18.2\%) were Coliform, $2(18.2 \%)$ were Staphylococcus aureus and 1 $(9.1 \%)$ was coagulase -ve staphylococcus (Please refer Table III).

\section{Antibiotic sensitivity status}

Highest sensitivity was with Ciprofloxacin and Amikacin in $8(72.2 \%)$ cases, followed by Cotrimoxazole which was sensitive in $7(63.6 \%)$ patients. Gentamycin was found sensitive in $4(36.3 \%)$ cases. Cefixime had the highest resistance $(100 \%)$, followed by Amoxicillin-
Clavulanic acid 8(72.7\%), Azithromycin 7(63.6\%), and Ceftriaxone 6(54.5\%) (Please refer Table IV).

Table III: Organisms found in culture-positive cases $(\mathrm{n}=11)$

\begin{tabular}{lcc}
\hline Culture result & $\begin{array}{c}\text { Number } \\
\text { of } \\
\text { patients }\end{array}$ & Percentage \\
\hline Klebsiella & 6 & 54.5 \\
Coliform & 2 & 18.2 \\
Staphylococcus aureus & 2 & 18.2 \\
Coagulase -ve & 1 & 9.1 \\
staphylococcus & &
\end{tabular}

\section{Association between blood culture with demographic variable}

A majority $(45.5 \%)$ of the patients belonged to age 41 50 days in the blood culture-positive cases. The mean age was found to be $39.1 \pm 7.2$ days in positive blood culture and $42.5 \pm 7.5$ days in negative groups, respectively. Almost two-thirds (63.6\%) of the patients were female in the positive blood culture group and one -third $(42.1 \%)$ in the negative group. Almost two-thirds of the mothers were housewives in both blood culture positive and negative cases. Blood culture positive cases were all $(100.0 \%)$ from the rural area, wherein the negative group, this was in $80.3 \%$ cases. Most of the patients were delivered at home in both positive (81.8\%) and negative $61(80.3 \%)$ cases. Overall, the variables the differences were not statistically significant among blood culture positive and negative cases. (Table V)

\section{Correlation between blood culture positivity with the sign of very severe disease}

Convulsion was found in three of the eleven $(27.3 \%)$ culture-positive cases and $23(30.3 \%)$ of the negative patients. Eight (72.7\%) patients had unable to feed in positive blood culture cases and $49(64.5 \%)$ in negative cases. Two $(18.2 \%)$ patients had grunting in positive blood culture and $14(18.4 \%)$ in the negative group. Seventy-one (93.4\%) patients had fast breathing in negative blood culture and not found in positive blood culture. All $(100.0 \%)$ patients had a fever in positive blood culture and $74(97.4 \%)$ in the negative cases. Two (2.6\%) patients had low body temperature in negative blood culture and were not found in the positive blood culture group. Two (18.2\%) patients had movement when stimulated in positive blood culture and 22 
Table IV: Distribution of the study patients by antibiotic sensitivity status $(n=11)$

\begin{tabular}{|c|c|c|c|c|c|c|}
\hline \multirow[t]{2}{*}{ Antibiotic } & \multicolumn{3}{|c|}{$\begin{array}{l}\text { Sensitive } \\
(n=11)\end{array}$} & \multicolumn{2}{|l|}{$\begin{array}{l}\text { Intermediate } \\
\text { sensitive }(n=11)\end{array}$} & \multirow{2}{*}{$\begin{array}{c}\begin{array}{c}\text { Resistant } \\
(\mathrm{n}=11)\end{array} \\
\%\end{array}$} \\
\hline & $\mathrm{n}$ & $\%$ & $\mathbf{n}$ & $\%$ & $\mathbf{N}$ & \\
\hline Amoxicillin + Clavulanic Acid & 0 & 0 & 3 & 27.2 & 8 & 72.72 \\
\hline Amikacin & 8 & 72.72 & 0 & 0 & 3 & 27.2 \\
\hline Azithromycin & 3 & 27.2 & 0 & 0 & 7 & 63.6 \\
\hline Cefixime & 0 & 0 & 0 & 0 & 11 & 100 \\
\hline Ceftazidime & 1 & 9.09 & 0 & 0 & 5 & 45.4 \\
\hline Ceftriaxone & 0 & 0 & 0 & 0 & 6 & 54.5 \\
\hline Cefuroxime & 0 & 0 & 0 & 0 & 1 & 9.09 \\
\hline Co-Trimoxazole & 7 & 63.6 & 0 & 0 & 2 & 18.1 \\
\hline Ciprofloxacin & 8 & 72.7 & 3 & 27.2 & 0 & 0 \\
\hline Gentamycin & 3 & 27.2 & 4 & 36.3 & 2 & 18.1 \\
\hline Imipenem & 3 & 27.2 & 1 & 9.1 & 1 & 9.1 \\
\hline Levofloxacin & 2 & 18.1 & 0 & 0 & 2 & 18.1 \\
\hline Lomefloxacin & 2 & 18.2 & 0 & 0 & 2 & 18.1 \\
\hline Meropenem & 1 & 9.1 & 0 & 0 & 1 & 9.1 \\
\hline Netilmicin & 1 & 9.1 & 0 & 0 & 0 & 0 \\
\hline Piperacillin Tazobactam & 3 & 27.2 & 0 & 0 & 1 & 9.1 \\
\hline Vancomycin & 0 & 0 & 0 & 0 & 2 & 18.1 \\
\hline
\end{tabular}

$(28.9 \%)$ in negative blood culture cases. Signs of very severe disease were not statistically significant concerning blood culture yield (Please refer Table VI).

\section{DISCUSSION}

This descriptive cross-sectional study was carried out to assess clinical characteristics of very severe disease according to WHO IMCI guideline among young infants of 29-59 days age and to determine whether clinically severe infections are associated with culturepositive bacteremia, and to find out common etiological factors including organisms involved.

A total of 87 infants of 29-59 days presenting with the features of very severe disease (according to the IMCI guideline), admitted in the pediatrics department of Chittagong Medical College were enrolled in the study. Infants with a congenital anomaly and those who were very sick were excluded from the study. The present study findings were discussed and compared with previously published relevant studies.

In this study, it was observed that the majority $(43.8 \%)$ of the patients belonged to age 31-40 days and the mean age was $42.2 \pm 7.4$ days, ranging from 30 to 57 days. No IMJM Volume 20 No.1, Jan 2021 study was found to compare the situation, for the inadequacy of research done on the target population. In a study done in Bangladesh, Darmstadt et al. took infants aged 1 week to 2 months presenting at the outpatient or emergency department of a tertiary care hospital with very severe disease, and the mean age of young infants was 32 days (range, 7-59 days); 72\% were male. $^{3}$

In this current study, it was observed that the majority $(55.2 \%)$ of patients were male and $44.8 \%$ were female. Kalter et al. ${ }^{8}$ also found most $(72 \%)$ of their study population to be male. Similarly, Darmstadt et al. ${ }^{3}$ found $42.0 \%$ of their $₫ 60$ days study patients to be female.

In this series, it was observed that the majority $(79.3 \%)$ of the mothers were housewives and $82.8 \%$ came from the rural area. $80.5 \%$ of the study infants were home delivered. Almost all $(96.6 \%)$ of the patients in our study were found to have received appropriate care of the umbilicus.

The WHO young infants clinical signs study group has identified in their large multicenter study $(n=8889)$ that, the seven signs of very severe disease have $74 \%$ sensitivity and $79 \%$ specificity in clinically predicting 
Table V: Association between blood culture with demographic variable $(n=87)$

\begin{tabular}{|c|c|c|c|c|c|}
\hline \multirow[t]{3}{*}{ Demographic variable } & \multicolumn{4}{|c|}{ Blood culture } & \multirow[t]{3}{*}{$\mathrm{p}$ value } \\
\hline & \multicolumn{2}{|c|}{$\begin{array}{c}\text { Positive } \\
(n=11)\end{array}$} & \multicolumn{2}{|c|}{$\begin{array}{c}\text { Negative } \\
(n=76)\end{array}$} & \\
\hline & $\mathrm{n}$ & $\%$ & $\mathrm{n}$ & $\%$ & \\
\hline \multicolumn{6}{|l|}{ Age (in days) } \\
\hline $29-38$ & 4 & 36.4 & 25 & 32.9 & \\
\hline $39-48$ & 6 & 54.5 & 36 & 47.4 & \\
\hline $49-58$ & 1 & 9.1 & 15 & 19.7 & \\
\hline$\overline{M e a n} \pm$ SD & \multicolumn{2}{|c|}{$39.1 \pm 7.2$} & \multicolumn{2}{|c|}{$42.5 \pm 7.5$} & $\mathrm{a} 0.162^{\mathrm{ns}}$ \\
\hline Range (min, max) & \multicolumn{2}{|c|}{30,54} & \multicolumn{2}{|c|}{30,57} & \\
\hline \multicolumn{6}{|l|}{ Gender } \\
\hline Male & 4 & 36.4 & 44 & 57.9 & $\mathrm{~b} 0.155^{\mathrm{ns}}$ \\
\hline Female & 7 & 63.6 & 32 & 42.1 & \\
\hline \multicolumn{6}{|l|}{ Mother's occupation } \\
\hline Housewife & 7 & 63.6 & 62 & 81.6 & $\mathrm{~b} 0.163^{\mathrm{ns}}$ \\
\hline Service holder & 4 & 36.4 & 14 & 18.4 & \\
\hline \multicolumn{6}{|l|}{ Residence } \\
\hline Urban & 0 & 0.0 & 15 & 19.7 & $\mathrm{~b} 0.108^{\mathrm{ns}}$ \\
\hline Rural & 11 & 100.0 & 61 & 80.3 & \\
\hline \multicolumn{6}{|l|}{ Place of delivery } \\
\hline Home & 9 & 81.8 & 61 & 80.3 & $\mathrm{~b} 0.634^{\mathrm{ns}}$ \\
\hline Institutional & 2 & 18.2 & 15 & 19.7 & \\
\hline
\end{tabular}

sepsis in neonates and young infants. ${ }^{16}$ Signs of severe Infection as found in our study was that the majority $(97.7 \%)$ of the patients had a fever, followed by fast breathing $(81.6 \%)$, history of unable to feed $(65.5 \%)$, convulsion (29.9\%), movement when stimulated (27.6\%), as well as $18.4 \%$ had grunting and only $2.3 \%$ had low body temperature. In the review by Opiyo \& English, that reviewed five large prospective observational studies ( $\mathrm{n}=17,506$ infants) and it was shown that fever, fast breathing, and history of unable to feed were the commonest signs of very severe disease among 0-59 days infants and had the highest predictive value in diagnosing very severe disease or severe infection in these children. ${ }^{11}$ English et al. had a similar finding in their study. ${ }^{6}$ The above findings are consistent with the present study.

In this study, it was observed that blood culture was positive in $12.6 \%$ of cases. It was shown by Downie et al. ${ }^{4}$ in their meta-analysis that, when it was reported, the range of prevalence of bacteremia in infants for whom a blood culture was performed was 3-16\% In the large six countries multi-center study by Hamer et al. $10.9 \%$ of infants 7-59 days of age infants had blood culture positivity. Similarly, Talbert et $a . .^{13}$ found in the out-born young infants, $10.0 \%$ had a positive blood culture, which is consistent with the present study.
Eleven patients were found in blood culture positive. Among them, Klebsiella was the most prevalent pathogen, comprising $6(54.5 \%)$ of the isolates, followed by coliform 2 (18.2\%), Staphylococcus Aureus 2(18.2\%), and coagulase -ve staphylococcus was $1(9.1 \%)$. In the meta-analysis by Downie et al. ${ }^{4}$ among infants of $29-90$ days, the most prevalent pathogens were $S$ aureus, E Coli, Klebsiella spp., Salmonella spp. and Streptococcus Pneumoniae, accounting for $59 \%$ (26-92\%) of positive sepsis cases. Another study from a resource-poor country also demonstrated Klebsiella sp. to be the most common pathogen in severe young infant sepsis as in our study. ${ }^{20}$

Among the 11 patients with whom the blood culture was positive, the most sensitive drugs were Ciprofloxacin and Amikacin (72.2\%), followed by Cotrimoxazole (63.6\%). Cefixime was found resistant in all $(100 \%)$ cases. Other resistant drugs were Amoxicillin -Clavulanic acid 8 (72.7\%), Azithromycin 7 (63.6\%), and Ceftriaxone $6(54.5 \%)$.

In this series, it was observed that the majority (45.5\%) patients belonged to age 41-50 days in positive blood culture and $23(30.3 \%)$ in negative blood culture. The mean age was found $39.1 \pm 7.2$ days in blood culturepositive cases and $42.5 \pm 7.5$ days in blood culturenegative cases. Almost two-thirds (63.6\%) patients were 
Table VI: Correlations between blood culture positivity with signs of austere disease ( $\mathrm{n}=87)$

\begin{tabular}{|c|c|c|c|c|c|}
\hline \multirow[t]{3}{*}{ Sign of severe infection } & \multicolumn{4}{|c|}{ Blood culture } & \multirow[t]{3}{*}{$\mathrm{p}$ value } \\
\hline & \multicolumn{2}{|c|}{$\begin{array}{c}\text { Positive } \\
(n=11)\end{array}$} & \multicolumn{2}{|c|}{$\begin{array}{c}\text { Negative } \\
(n=76)\end{array}$} & \\
\hline & $\mathrm{n}$ & $\%$ & $\mathrm{n}$ & $\%$ & \\
\hline \multicolumn{6}{|l|}{ Convulsion } \\
\hline Yes & 3 & 27.3 & 23 & 30.3 & $0.573^{\mathrm{ns}}$ \\
\hline No & 8 & 72.7 & 53 & 69.7 & \\
\hline \multicolumn{6}{|l|}{ Unable to feed } \\
\hline Yes & 8 & 72.7 & 49 & 64.5 & $0.432^{\mathrm{ns}}$ \\
\hline No & 3 & 27.3 & 27 & 35.5 & \\
\hline \multicolumn{6}{|l|}{ Grunting } \\
\hline Yes & 2 & 18.2 & 14 & 18.4 & $0.674^{\mathrm{ns}}$ \\
\hline No & 9 & 81.8 & 62 & 81.6 & \\
\hline \multicolumn{6}{|l|}{ Fast breathing } \\
\hline Yes & 0 & 0.0 & 71 & 93.4 & $0.001^{\mathrm{s}}$ \\
\hline No & 11 & 100.0 & 5 & 6.6 & \\
\hline \multicolumn{6}{|l|}{ Fever } \\
\hline Yes & 11 & 100.0 & 74 & 97.4 & $0.762^{\mathrm{ns}}$ \\
\hline No & 0 & 0.0 & 2 & 2.6 & \\
\hline \multicolumn{6}{|l|}{ Low body temperature } \\
\hline Yes & 0 & 0.0 & 2 & 2.6 & $0.762^{\mathrm{ns}}$ \\
\hline No & 11 & 100.0 & 74 & 97.4 & \\
\hline \multicolumn{6}{|c|}{ Movement when stimulated } \\
\hline Yes & 2 & 18.2 & 22 & 28.9 & $0.365^{\mathrm{ns}}$ \\
\hline No & 9 & 81.8 & 54 & 71.1 & \\
\hline
\end{tabular}

female in positive blood culture and $32(42.1 \%)$ in negative blood culture cases. The majority $(63.6 \%)$ of the mother were housewives in positive blood culture and $62(81.6 \%)$ in negative blood culture. All (100.0\%) patients were from the rural area in positive blood culture and $61(80.3 \%)$ in negative blood culture. Most $(81.8 \%)$ patients were delivered at home in positive blood culture cases and $61(80.3 \%)$ in negative cases. No statistically significant association was found for any of the demographic variables between the blood culture positive and negative cases. Culture positivity rates varied significantly, with reported rates as high as $65.0 \%$ obtained by Tallur et al. ${ }^{14}$ and as low as $5.0 \%$ reported by Hamer et al. ${ }^{7}$

In this series it was found that in blood culture-positive cases, all $(100 \%)$ had a fever, $72.7 \%$ had a history of unable to feed, $27.3 \%$ had convulsions and $18.2 \%$ had movement only when stimulated, whereas in blood culture-negative cases fever was also present in almost all $(97.4 \%)$ of the cases, history of unable to feed was present in $64.5 \%$, fast breathing in $93.4 \%$, grunting in $18.4 \%$ and $2.6 \%$ had low body temperature. No statistically significant association was found between blood culture positivity and the presence of one or the other sign of austere diseases in the patients. There was no study found that evaluated the association of IMJM Volume 20 No.1, Jan 2021 presence or absence of any of the signs of very severe disease with that of the blood culture yield.

\section{CONCLUSION}

Very severe disease according to the WHO IMCI guideline is rather a clinical diagnosis because the diagnostic yield of blood culture positivity is very low in these patients. The study has shown this very result. Fever, fast breathing, unable to feed were found to be the predictors of very severe disease in this age group. The patients with positive blood culture had Klebsiella spp. as the commonest bacteria causing the illness, and the antibiotic sensitivity pattern has been changing over the years. To establish a bacteriological diagnosis and show the antibiotic sensitivity pattern a PCR or molecular-based study could be undertaken in the future.

\section{LIMITATIONS OF THE STUDY}

The main limitations of the study were that the study population was relatively smaller and was done over a shorter period. The patient population may not also be fully representative of the country, as they were selected from a selected hospital in Chittagong city. 


\section{RECOMMENDATION}

Further studies are needed to be done by including a larger number of patients.

\section{REFERENCES}

1. Bhutta Z A, Darmstadt G L, Ransom E I. Using evidence to save newborn lives. Policy perspectives on newborn health. 2003.

2. Coghill J K, D E Simkiss. Which clinical signs predict severe illness in children less than 2 months of age in resource poor countries? Arch Dis Child 2011;96: A74.

3. Darmstadt G L, Saha S K, Choi Y, et al. Population-based incidence and etiology of community-acquired neonatal bacteraemia in Mirzapur, Bangladesh: an observational study. J Infect Dis. 2009; 200:906-915.

4. Downie L, Armiento R, Subhi R, Kelly J, Clifford V, Duke T. Community-acquired neonatal and infant sepsis in developing countries: efficacy of WHO's currently recommended antibiotics-systematic review and meta-analysis. Arch Dis Child. 2013; 98:146-154.

5. Duke T, Oa O, Mokela D, Oswyn G, Hwaihwanje I, Hawap J. The management of sick young infants at primary health centres in a rural developing country. Arch. Dis. Child. 2005; 90:200-205.

6. English M, Ngama M, Mwalekwa L, Peshu N. Signs of illness in Kenyan infants aged less than 60 days. Bull World Health Organ 2004; 82:323-9.

7. Hamer D H, Darmstadt G L, Carlin J B, et al. Etiology of Bacteremia in Young Infants in Six Countries. Pediatr Infect Dis J. 2015;34(1): e1-8.

8. Kalter H D, Schillinger J A, Hossain M, et al. Identifying sick children requiring referral to hospital in Bangladesh. Bulletin of the World Health Organization, 1997,75 (Supplement 1): 65-75.

9. Klein JO. Bacterial sepsis and meningitis. In: Remington JS, Klein JO, eds. Infectious
Diseases of the Fetus, Newborn, and Infants. 5th ed. Philadelphia, PA: WB Saunders; 2001:943-984.

10. Lawn J E, Cousens S, Zupan J. 4 million neonatal deaths: when? where? why? Lancet. 2005; 365:891-900.

11. Opiyo N, English M. What clinical signs best identify severe illness in young infants aged 0-59 days in developing countries? A systematic review. Arch Dis Child 2011; 96:1052-1059.

12. Stoll B J. Infections of the Neonatal Infant: Pathogenesis and Epidemiology. In: Nelson Textbook of Pediatrics. 19th ed. Saunders; 2011:629-648.

13. Talbert A W, Mwaniki M, Mwarumba S, Newton C R, Berkley J A. Invasive bacterial infections in neonates and young infants born outside hospital admitted to a rural hospital in Kenya. Pediatr Infect Dis J. 2010;29: 945-949.

14. Tallur S S, Kasturi A, Nadgir S, Krishna B. Clinico-bacteriological study of neonatal septicemia in Hubli. Ind J Pediatr. 2000; 67:169-74.

15. UNICEF, WHO, World Bank, UN DESA/ Population Division. Levels and Trends in Child Mortality 2015.UNICEF,2015.

16. Young Infants Clinical Signs Study Group. Clinical signs that predict severe illness in children under age 2 months: a multicentre study. Lancet 2008;371:97-8

17. Weber M, Carlin J, Gatchalian S, et al. Predictors of neonatal sepsis in developing countries. Pediatr Infect Dis J 2003; 22:711 -16 .

18. World Health Organization. GUIDELINE Managing possible serious bacterial infection in young infants when referral is not feasible. WHO 2015 ISBN-13: 978-92-4-150926-8

19. World Health Organization. Integrated management of childhood Illness Chart Booklet, March2014. WHO 2014.

20. Zaidi A K M, Thaver D, Ali S A, Khan T

A. Pathogens Associated with Sepsis in Newborns and Young Infants in Developing Countries. Pediatr Infect Dis J. 2009;28: S10-S18. 